\title{
Análise de regularidades metodológicas em pesquisas brasileiras sobre comportamentos de uso e usuários da informação
}

\author{
Hamilton Rodrigues Tabosa * \\ Virgínia Bentes Pinto \\ José Mauro Matheus Loureiro **
}

Artículo recibido:

27 de noviembre de 2013.

Artículo aceptado:

13 de octubre de 2015.

\section{Resumo}

Objetiva investigar as contribuições de pesquisadores brasileiros, dentro dos estudos de uso e usuários da informação, a partir da análise de vinte e duas dissertações e quatro teses, no que se refere a metodologias empregadas nesses estudos e seus principais resultados na última década. Identifica regularidades nas metodologias frequentemente utilizadas e analisa indícios de padronização metodológica nessa área de investigação da Ciência da Informação (CI), bem como aglutina e analisa os principais resultados dessas pesquisas que,

Universidade Federal do Ceará, Brasil. (hrtabosa@gmail.com); (bentespinto@yahoo.com.br)

** Universidade Federal do Estado do Rio de Janeiro, Brasil. jmmloureiro@gmail.com

INVESTIGACIÓN BIBLIOTECOLÓGICA, Vol. 30, Núm. 70, septiembre/diciembre, 2016, México, ISSN: 0187-358X. pp. 249-267 
consequentemente, colaboram para a construção teórica e metodológica na CI. Apresenta conceitos de metodologia e aspectos da construção metodológica da Ciência da Informação como uma Ciência Social. Os resultados indicam coerência nas escolhas metodológicas dos trabalhos investigados, bem como apontam regularidades na adoção de métodos e técnicas oriundas das Ciências Sociais, tais como preferência por pesquisas qualitativas, uso de entrevistas, questionários, estudos de caso, entre outros. Os resultados apresentam também haver regularidades quanto a certas conclusões a que chegaram as dissertações e teses a respeito dos comportamentos de busca e uso de informação.

Palavras-chave: Ciência da Informação - metodologia; Ciência da Informação - pesquisa; Comportamentos de busca e uso da informação; Estudo de usuários.

\section{Abstract}

Analysis of methodological regularity in Brazilian research on information user behaviors

Hamilton Rodrigues-Tabosa, Virgínia Bentes-Pinto and José-Mauro Matheus-Loureiro

This paper examines the contributions of Brazilian researchers in the field of information use and users, through an analysis of methodologies employed in twenty-two research paper and four theses published in the last decade, while also examining their results. By identifying the frequency of the methodological approaches employed, we attempt to find evidence of methodological standardization in the field of Information Science (IS) research. Moreover, by gathering the results of these surveys, our aim is to facilitate the methodological and theoretical construction of IS. This paper introduces the concept of methodology and methodological aspects of the construction of Information Science as a social science. Results indicate consistency in methodological choices of the sample works and regularities in the adoption of methods and techniques habitually employed in the social sciences, such as the preference for qualitative research, use of interviews, questionnaires and case studies. Moreover, the research finds regularities in certain conclusions 
regarding the thesis regarding search behavior and use of information.

Keywords: Information Science - methodology; Information Science - research; Seeking behaviors and use of information; Study users.

\section{INTRODUÇÃO}

$\mathrm{O}$ estudo das necessidades de informação, dos comportamentos de busca e dos usos da informação das pessoas individualmente ou de um determinado grupo social pode ser considerado como um método de investigação científica de um fenômeno social que a Ciência da Informação (CI) denomina estudos de uso e usuários da informação. Identificados por Araújo (2009) como corrente teórica da CI, os estudos de uso e usuários apresentam uma perspectiva cognitivista, buscando entender a informação a partir das estruturas mentais dos usuários que se relacionam com a informação (que necessitam que buscam e que a usam). Conforme esse autor, esses estudos partem das percepções dos usuários em relação às suas necessidades de informação, os caminhos percorridos para saciar essas necessidades e o uso da informação para a execução de determinada tarefa ou para solucionar um problema.

A literatura em CI aponta na direção da carência de padronização metodológica nas pesquisas da área, tendo importado muitas abordagens, modelos e técnicas das ciências humanas e sociais, isso depois de ela própria ter começado a procurar se afastar do positivismo (muito embora em certos casos o viés positivista ainda permaneça), passando a transpor gradativamente o paradigma físico, e passado a se esforçar para se reconhecer como ciência social e começado a acumular conhecimentos que, posteirormente, viriam a consolidar suas próprias teorias e métodos. Para González de Gómez (2007), essa pluralidade metodológica é própria das ciências sociais e interdisciplinares como a CI.

Pinheiro (2005) destaca que, no Brasil, os estudos de cunho teórico, metodológico e epistemológico na área de CI, acompanham o cenário internacional no que se refere ao baixo número de publicações, se comparado a outras áreas de especialidades dentro da CI, o que torna interessantes e necessárias iniciativas de investigações teóricas nessa área. No Brasil, existem hoje vários pesquisadores que se debruçam sobre essa corrente teórica da CI que diz respeito ao estudo dos comportamentos de busca e uso da informação. 
Este estudo constitui-se de uma análise das contribuições de pesquisadores brasileiros, dentro do escopo dos estudos de uso e usuários da informação, a partir da análise de dissertações e teses, no que se refere a metodologias empregadas nesses estudos e seus principais resultados na última década. Com isso, objetivamos identificar regularidades nas metodologias predominantemente utilizadas e analisar os avanços teóricos e indícios de padronização metodológica nessa área de investigação da CI no Brasil, bem como aglutinar e analisar os principais resultados dessas pesquisas que, consequentemente, colaboram para a construção teórica e metodológica na CI.

Para o desenvolvimento deste estudo, foram selecionados vinte e seis relatórios de pesquisa, sendo vinte e duas dissertações e quatro teses, defendidas em programas de pós-graduação em CI no Brasil a partir de 2000, por meio de consultas à Biblioteca Digital Brasileira de Teses e Dissertações (BDTD ${ }^{1}$ e nos repositórios institucionais das universidades onde funcionam cursos de pós-graduação em nível de mestrado e/ou doutorado.

O corpus documental para o estudo foi selecionado por meio da utilização do campo de busca avançada presente nas interfaces dos bancos de dados, e que respondeu a estratégias de buscas com os operadores booleanos "e" e "ou", ou equivalentes, empregados para ligar os termos "necessidade", "informação", "uso", "usuários" e "comportamento", que aparecessem no resumo das dissertações ou teses, para identificar pesquisas que tivessem como temática principal os estudos sobre comportamentos de busca e uso da informação.

Foi criada uma planilha para consolidar os dados e facilitar a leitura a partir das categorias: autor, tipo de trabalho (dissertação ou tese), objetivo geral, metodologia e resultados. O objetivo geral de cada trabalho foi transcrito fielmente na coluna correspondente, porém, na coluna que coube à determinação da metodologia, foram usados termos e expressões resumidas para indicar a escolha metodológica do pesquisador, com relação ao método, tipo de pesquisa quanto aos objetivos (exploratória, descritiva, dentre outros), natureza (qualitativa, quantitativa, etc.), técnica de coleta de dados (entrevistas, questionários e sua tipologia, etc.), técnica de análise de dados (análise do discurso, análise de conteúdo, etc.), e assim por diante. Também foi feita a transcrição de trechos retirados do resumo e/ou do capítulo destinado à análise dos dados e/ou da conclusão de cada trabalho, para identificar os principais resultados alcançados por cada pesquisa, no intuito de se traçar um panorama das contribuições dos pesquisadores brasileiros no que diz respeito à construção do conhecimento científico em CI. 


\section{Metodologia: o ESTUdo do MÉTOdo}

A finalidade da pesquisa científica é descobrir respostas para questões mediante a aplicação de métodos científicos. Embora esses métodos nem sempre sejam capazes de gerar respostas absolutamente irrefutáveis, dadas suas características e limitações, muitas vezes são os únicos que podem oferecer resultados satisfatórios e/ou razoavelmente confiáveis, conforme Lakatos e Marconi (1996).

Ainda segundo esses autores, a Metodologia objetiva identificar e analisar os aspectos distintivos dos vários métodos imprescindíveis a uma investigação, avaliar seu alcance, suas potencialidades, seus limites ou capacidade de causar distorções e criticar os pressupostos ou aquilo que sua utilização pode acarretar. É na Metodologia que são traçadas com precisão, minúcia e rigor todas as ações desenvolvidas no método (caminho) do trabalho de pesquisa. É o detalhamento da tipologia da pesquisa, da sua instrumentalização, do tempo previsto para sua execução, do staff e da divisão das tarefas, embora muitas vezes o pesquisador trabalhe sozinho, das técnicas escolhidas para o tratamento quantitativo, qualitativo ou misto dos dados, ou seja, de todo o material empregado nas diferentes etapas da pesquisa e do passo a passo que o pesquisador percorreu, de modo que a pesquisa possa ser reproduzida por outro pesquisador.

Richardson (1999) preceitua que os pensadores Francis Bacon e René Descartes foram os que mais se destacaram no desenvolvimento de um método geral de conhecimento e continua: "o método científico é um conjunto de regras para observar fenômenos e inferir conclusões" (1999: 22). Segundo Lakatos e Marconi (1996), o método é o somatório das atividades sistemáticas e racionais que, promovendo maior segurança e economia, permite se atingir o objetivo da pesquisa gerando conhecimentos válidos e verdadeiros, traçando o caminho a ser percorrido ou que escolhas devem ser feitas, detectando equívocos e inexatidões e auxiliando a tomada de decisão dos cientistas.

Considerando que o ato de classificar exige a demarcação de algum parâmetro, os tipos de pesquisa são classificados de acordo com critérios empregados pelos metodólogos. Sem a intenção de elencar todas as possibilidades de classificação, destacamos abaixo algumas principais classificações de pesquisa encontradas na literatura e que foram utilizadas para a instrumentalização do estudo desenvolvido neste artigo:

- Quanto à natureza (Silva, 2004):

- Pesquisa Básica - objetiva gerar conhecimentos novos úteis para o avanço da ciência sem aplicação prática prevista. Envolve verdades e interesses universais. 
- Pesquisa Aplicada - objetiva gerar conhecimentos para aplicação prática dirigida à solução de problemas específicos. Envolve verdades e interesses locais.

- Quanto à forma de abordagem (Gil, 1996):

- Pesquisa Quantitativa - considera que tudo pode ser quantificável, o que significa traduzir em números opiniões e informações para classificá-los e analisá-los.

- Pesquisa Qualitativa - considera que há uma relação dinâmica entre o mundo real e o sujeito, isto é, um vínculo indissociável entre o mundo objetivo e a subjetividade do sujeito que não pode ser traduzido em números. A interpretação dos fenômenos e a atribuição de significados são básicos no processo de pesquisa qualitativa.

- Quanto aos objetivos (Gil, 1996):

- Pesquisa Exploratória - visa proporcionar maior familiaridade com o problema com vistas a torná-lo explícito ou a construir hipóteses. Envolve levantamento bibliográfico; entrevistas com pessoas que tiveram experiências práticas com o problema pesquisado; análise de exemplos que estimulem a compreensão. Assume, em geral, as formas de Pesquisas Bibliográficas e Estudos de caso.

- Pesquisa Descritiva - visa descrever as características de determinada população ou fenômeno ou o estabelecimento de relações entre variáveis. Envolvem o uso de técnicas padronizadas de coleta de dados: questionário e observação sistemática. Assume, em geral, a forma de Levantamento.

- Pesquisa Explicativa - visa identificar os fatores que determinam ou contribuem para a ocorrência dos fenômenos. Aprofunda o conhecimento da realidade porque explica a razão, o "porquê" das coisas. Quando realizada nas ciências naturais requer o uso do método experimental e nas ciências sociais requer o uso do método observacional. Assume, em geral, a formas de Pesquisa Experimental e Pesquisa Ex-post-facto.

- Quanto aos procedimentos técnicos (Silva, 2004):

- Pesquisa Bibliográfica - quando elaborada a partir de material já publicado, constituído principalmente de livros, artigos de periódicos, etc.

- Pesquisa Documental - quando elaborada a partir de materiais que não receberam tratamento analítico.

- Pesquisa Experimental - quando se determina um objeto de estudo, selecionam-se as variáveis que seriam capazes de influenciá-lo, definem-se as formas de controle e de observação dos efeitos que a variável produz no objeto. 
- Levantamento - quando a pesquisa envolve a interrogação direta das pessoas cujo comportamento se deseja conhecer.

- Estudo de caso - quando envolve o estudo profundo e exaustivo de um ou poucos objetos de maneira que se permita o seu amplo e detalhado conhecimento.

- Pesquisa Ex-Post-Facto - quando o "experimento" se realiza depois dos fatos.

- Pesquisa ação - quando concebida e realizada em estreita associação com uma ação ou com a resolução de um problema coletivo.

- Pesquisa Participante - quando se desenvolve a partir da interação entre pesquisadores e membros das situações investigadas.

Destacamos que alguns dos tipos de pesquisa identificados acima não são excludentes e podem ser empregados em consórcio, de maneira complementar, a critério do pesquisador, para melhor compreensão do seu objeto de estudo.

\section{A CONSTRuÇÃo metodológica EM CiênCia da Informação: uma Ciência Social}

Considerando a gênese formal da CI ligada às ciências exatas, sobretudo à Ciência da Computação e aos modelos explicativos da transmissão e recuperação da informação por máquina, com a Teoria Matemática da Comunicação, no final do século XX ela passou a se esforçar para se inscrever efetivamente dentre as Ciências Sociais (CS) (Araújo, 2003), afastando-se daqueles posicionamentos inicias baseados no empirismo e tecnicismo positivistas, vindo a assentar-se, de fato, como CS na década de 80 (Linares Columbié, 2010).

Richardson (1999) explorando o pensamento de Georgen, afirma que a pesquisa no campo das Ciências Sociais não pode negligenciar a reflexão sobre o contexto conceitual, histórico e social que forma o horizonte mais amplo dentro do qual as pesquisas isoladas obtêm o seu sentido. A partir desse argumento, a CI passou então a incorporar em seus estudos os aspectos sociais, culturais e históricos envolvidos nos processos de informação, desvencilhando-se do paradigma físico e abrindo espaço para o cognitivo e depois o social, como assevera Capurro (2003).

A Ciência pode ser dividida em Formal e Factual, estando a CI entre as factuais, conforme ensinam Lakatos e Marconi (1996), uma vez que ela estuda fatos (objetos empíricos, coisas e processos) que, reconstruídos pelo olhar 
do pesquisador, precisam ser analisados com o intuito de se refutar ou comprovar hipóteses, em sua maioria, provisórias.

Para a construção do conhecimento científico, as CS utilizam metodologias quantitativas ou qualitativas, constituídas de inúmeros métodos, conforme vimos na seção anterior, métodos esses que a CI absorveu e que vêm sendo utilizados pelos pesquisadores da área.

Para Silva (2008), a CI, nos primeiros momentos da sua migração para o campo das CS, utilizou-se de métodos quantitativos e teria assumido uma postura de pretensa imparcialidade (resquício do positivismo), porém, na maioria de seus estudos, não teria logrado êxito quanto a essa neutralidade. Segundo esse autor, essa fase foi vencida pela adoção de ideias marxistas, de modo que o fazer científico passou a ser questionado e novos elementos foram sendo agregados à análise dos objetos de estudo. Como havia afirmado Richardson (1999), a historicidade, os aspectos e fenômenos sociais despertaram o interesse da CI, bem como a "compreensão da tensionalidade constante nas relações de luta de poder expandem uma teoria crítica sobre diversos aspectos das práticas na área” (Silva, 2008: 67). No entanto, Araújo (2003: 25) enfatiza que "É, apenas com a aproximação junto ao 'terceiro ramo' das ciências sociais, isto é, aos enfoques microssociológicos e interpretativos, que a Ciência da Informação vai conhecer uma reformulação mais profunda de seus pressupostos, que vai alterar sobretudo o significado do que é entendido como “informação'”.

Dentre as principais correntes teóricas desenvolvidas nesse "terceiro ramo" das CS, Silva (2008) destaca a Sociologia Interpretativa de Weber e o enfoque microssociológico de Simmel e identifica o Interacionismo Simbólico, a Fenomenologia e Etnometodologia como fontes de importantes contribuições à evolução da CI. A partir de então, a CI abriu-se a novas tendências no fazer científico da área da informação, como ressalta Araújo (2003).

Buscando sempre nas CS os métodos científicos para instrumentalizar seus estudos, a CI não teria desenvolvido seus próprios métodos de pesquisa, principalmente nos campos de investigação onde a subjetividade é mais latente, como por exemplo, os estudos de uso e usuários da informação. Assim, os pesquisadores da CI perceberam que levantamentos e aplicação de métodos estatísticos não eram suficientes para explicar a realidade e os fenômenos culturais e sociais envolvidos nesse tipo de pesquisa e passaram a buscar outros meios de instrumentalizar seus estudos.

Bettiol, na década de 1990, afirmava: "As descobertas no campo [dos estudos de uso e usuários] têm sido de difícil aplicação, ao que se atribui, frequentemente, à falta de uma teoria unificada, de uma metodologia padronizada e de definições comuns" (1990: 61). Case, já em 2007, ou seja, quase 
duas décadas depois, frisou que a falta de uma delimitação teórica continua a prejudicar a investigação empírica sobre busca de informações e sobre os comportamentos do usuário. González de Gómez (2000) ainda amplia essa noção de carência de padronização metodológica na CI, quando reforça o argumento de que toda a pesquisa nessa área, não se limitando ao âmbito dos estudos de uso e usuários da informação, não possui uma metodologia própria, devendo o pesquisador cuidar da adequação das estratégias metodológicas empregadas por ele à problemática do estudo em questão, já que, segundo a autora, a CI apresenta-se, desde seu início, como conjunto de saberes agregados antes por questões do que por teorias.

Esse estado teórico e metodológico incipiente se explica pelo fato de que, conforme já mencionado anteriormente, o positivismo predominou na CI por muitos anos, desde seu surgimento no início do século XX (considerando suas raízes na Documentação, criada por Otlet e La Fontaine), sendo suplantado somente no final daquele século, pelo advento do paradigma cognitivo e social vivenciado pela CI, conforme explica Capurro (2003), bem como por uma aparente ausência de identidade da CI, tendo surgido de uma teoria matemática e depois migrado para as CS, afirmando-se interdisciplinar tendo, no entanto, sua própria epistemologia ainda em discussão e inconclusa, conforme afirma Linares Columbié (2010).

A denominação Ciência da Informação surgiu somente em meados do século XX, mas somente na década de 90 é que alguns de seus princípios, teorias e métodos passaram a ser consolidados, como aponta Pinheiro (2005). Durante esse período de "amadurecimento", a CI passou por três fases de evolução, conforme a autora, e enfrentou os três paradigmas identificados por Capurro (2003).

Assim, o padigma cogtivivo, já na segunda metade do século XX, trouxe à baila outras preocupações para a CI, que passou a investigar o sujeito, o usuário da informação, suas necessidades, comportamentos de busca e uso da informação, superando o modelo de gestão custodial dos acervos. Podemos afirmar que os estudos nessa área são relativamente recentes e seus produtos intelectuais ainda incipientes, pela falta de delimitação consistente de suas metodologias e teorias (ou quase teorias, como ressalva Pinheiro (2005)) em que se acentam. É evidente que não se pode negligenciar a necessidade de um amadurecimento lento e gradual de uma ciência em busca de identidade, que ainda empreende esforços para melhor compreender e mesmo conceitualizar seu objeto de estudo. Devemos considerar também a subjetividade e a inescapável necessidade de abstração inerentes aos estudos de informação e, especialmente, de usuários da informação, seres sociais de difícil apreensão devido sua essência carregada de instabilidade. 
Por essas razões, evidentemente, nas CS não se pode aplicar as mesmas metodologias utilizadas nas ciências naturais. Daí a importância de se investigar regularides nas construções metodológicas das pesquisas em CI, de modo que possamos identificar e avaliar sua consistência.

\section{Alguns aspectos da Ciência da Informação no Brasil}

Conforme destaca Pinheiro (2005), os estudos de cunho teórico, metodológico e epistemológico na área de CI são escassos também no Brasil, devido aos cursos de pós-graduação no País terem começado e permanecido na área de Biblioteconomia, tendo alterado sua denominação para CI somente a partir da década de 90, além do que, o único programa que inclui uma linha de pesquisa sobre Epistemologia ser o Programa de Pós-Graduação em Ciência da Informação do IBICT. Quanto a linhas de pesquisa onde se enquadram estudos de comportamentos de busca, acesso, uso e usuários da informação, existem vários programas de pós-gradução que se dedicam a essa área de estudo no Brasil.

Assim como aconteceu com a própria denominação da área da CI e a consolidação de terminologias ao longo de suas três fases de evolução, conforme Pinheiro (2005), os estudos de uso e usuários da informação foram sofrendo mudanças de abordagem desde seu surgimento na segunda metade do século XX, tendo começado com estudos dos sistemas de informação, passando depois a investigar o indivíduo e, mais recentemente, o uso da informação. Essa área da CI vem, aos poucos, acumulando conhecimentos, o que torna investigações nessa área desejáveis e necessárias, visando à aglomeração de conhecimentos que possam subsidiar a consolidação de um corpo teórico e metodológico. $\mathrm{Na}$ atualidade, há vários pesquisadores empenhados em estudos de uso e usuários da informação no Brasil, cujas contribuições giram em torno de investigações sobre os comportamentos de busca, desenvolvimento de metodologias para os estudos de uso e usuários da informação ou sobre o uso feito de um determinado tipo de informação por grupos de pessoas ou comunidades específicas.

\section{ANÁlise das CONSTRUÇÕes METODOLÓGICAS EM DISSERTAÇÕES E TESES em CiÊNCIA da InformaÇão No Brasil}

Antes de apresentarmos os dados quantitativos e interpretá-los, faz-se oportuno refletirmos sobre a elevada diferença entre o número de dissertações (vinte e duas) e teses (quatro) identificadas e selecionadas para este estudo. É 
importante notar que os estudos de uso e usuários da informação, enquanto corrente teórica da CI, como assevera Araújo (2009), não esteja despertando tanto interesse de doutorandos no Brasil, da mesma forma como acontece com os mestrandos. A questão que se coloca é: se houve tantos mestrandos desenvolvendo pesquisas dessa natureza, por que essa proporção não se reflete no doutorado ${ }^{2}$ Ou seja, por qual motivo os mestres parecem não continuar seus estudos no doutorado a partir dos projetos que desenvolveram no mestrado? Essa realidade pode acarretar que não sejam realizados estudos nessa área com maior grau de complexidade e comprometer o surgimento de conhecimentos inéditos nesse ramo de investigação. Esse quadro tende a não favorecer o desenvolvimento da Ciência da Informação e, certamente, jamais colocará o Brasil na posição de vanguarda na produção de conhecimentos nessa área, restando-nos apenas a opção de assimilação, reprodução e adaptação de métodos, técnicas e teorias que não foram desenvolvidos a partir da nossa realidade, e que, provavelmente, não necessariamente se adequarão a nossas idiossincrasias, como tem acontecido ao longo do tempo, com a importação das leis, regras e códigos que regem o desenvolvimento de quadros teóricos e pragmáticos do profissional da informação no Brasil.

Nossa preocupação encontra fundamento quando observamos a classificação dos vinte e seis trabalhos analisados: quatorze se autoclassificaram como sendo de natureza qualitativa, nove como sendo quali-quantitativos e seis, ou seja, vinte e um por cento como sendo de natureza quantitativa. Isso se refletiu também na quantidade de estudos identificados pelos próprios pesquisadores como descritivos, representando trinta e um por cento do total (exploratórios, vinte e sete por cento, enquanto os exploratórios e descritivos representaram quarenta e dois por cento do total) (Figura 1 e Figura 2).

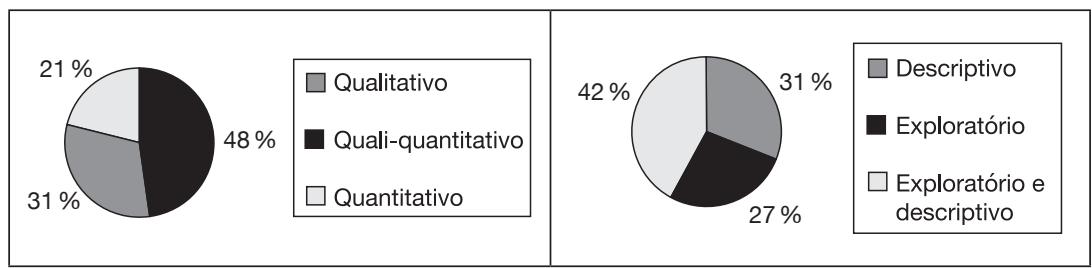

Figura 1. Quanto à forma de abordagem

Figura 2. Quanto a os objetivos

Mesmo considerando as diferentes abordagens e as diferentes variáveis que podem interferir no modo como se trabalha um determinado objeto de

2 Naturalmente, admitimos o fato de não haver tantas vagas em cursos de doutorado como há nos de mestrado, porém, o que destacamos aqui é a diferença na proporção. 
estudo, causou-nos admiração o fato de não haver sequer uma dissertação ou tese que tenha sido classificada quanto aos objetivos, como explicativa. Como vimos anteriormente, são as pesquisas explicativas que aprofundam o conhecimento da realidade, uma vez que explicam suas razões, suas causas. Outro ponto digno de nota é o fato de haver um percentual de pesquisas, que julgamos elevado, com foco apenas no aspecto quantitativo das realidades estudadas, ou apenas com o objetivo de levantar dados estatísticos e descrever uma realidade ou situação.

Assim, parece que parte dos pesquisadores em CI no Brasil estão sempre "explorando" temas e assuntos ainda pouco ou nunca estudados ou limitando-se a descrever a realidade, sem se preocupar com suas causas, em investigar mais profundamente as questões.

As escolhas metodológicas para coleta e tratamento dos dados feitas pelos mestrandos e doutorandos para estudar quantitativamente os que coletaram giraram em torno de questionários estruturados e uso de software capazes de realizar cálculos estatísticos, como o SPSS, EndNote, Ucinet e Excel, fundamentando suas escolhas na facilidade de tabulação, visualização de proporções, discrepâncias e geração de gráficos.

Com relação às pesquisas de natureza qualitativa, essas apresentaram maior pluralidade metodológica no que diz respeito às técnicas de coleta e análise dos dados. Nessa categoria, destacaram-se como recorrentes as técnicas de coleta de dados: entrevista semiestruturada, entrevista estruturada ou semiestruturada associada à aplicação da técnica do incidente crítico, ${ }^{3} \mathrm{o}$ questionário com perguntas fechadas e com perguntas abertas e fechadas, bem como a aplicação conjunta de questionário e entrevista semiestruturada.

Para o desenvolvimento de pesquisas de caráter qualitativo, essas escolhas pareceram-nos adequadas, pois possibilitam, por exemplo, no caso das entrevistas semiestruturadas, um maior aprofundamento das questões propostas por meio da interação face a face, retomada de pontos que não tenham sido bem esclarecidos, e pela possibilidade de percepção dos gestos e fisionomias dos sujeitos. Já quanto aos questionários, é sabido que as perguntas abertas ensejam respostas subjetivas que somente através de uma análise qualitativa é possível se atribuir sentido.

Dentro da categoria de pesquisas qualitativas, chamou-nos atenção o fato de haver também a aplicação de modelos clássicos de comportamento de

3 Técnica criada pelo psicólogo americano John C. Flanagan. Essa técnica tem sido aplicada tanto em campos das Ciências Sociais como na Saúde, Educação e Informação e que consiste em pedir ao entrevistado que, nesse caso, descreva a última ocasião em que necessitou de um determinado tipo de informação. Ver Flanagan (1954). 
busca e uso de informação como o proposto por Dervin ${ }^{4}$ (utilizado em dois trabalhos), o de Wilson (1996) (utilizado em um) e o de Ellis 5 (utilizado também em um). Esses modelos foram empregados para estudar realidades distintas, tendo sido corroborada sua eficiência e atualidade.

A técnica de análise dos dados das investigações de natureza qualitativa ou quali-quantitativa mais empregada foi a análise de conteúdo, ${ }^{6}$ aparecendo em segundo lugar a análise do discurso, ${ }^{7}$ como meios para se extrair sentido da subjetividade própria das respostas das questões abertas dos questionários e das transcrições dos depoimentos gravados das entrevistas. Pudemos verificar que em dezesseis por cento dos casos o autor da pesquisa disse apenas que realizou uma análise qualitativa dos dados coletados, ou que os dados qualitativos foram analisados "manualmente", no intuito de esclarecer que não foi utilizado nenhum software para trabalhar os dados, mas sem qualquer indicação da técnica de análise de dados aplicada.

A metodologia qualitativa não permite generalizações. Considera-se mais importante a descrição dos fenômenos em situação real, do que a extensão da amostragem. Não existem verdades absolutas e sim, as opiniões daqueles que participaram da coleta de dados, não negligenciando o fato de que agem sob subjetividades, enquanto o pesquisador é também um ser subjetivo. Ainda assim, os resultados de investigações qualitativas contribuem diretamente para uma melhor compreensão da realidade.

Assim, é salutar esclarecer que não é conveniente menosprezar ou subestimar o potencial que uma análise qualitativa de dados tem de promover a compreensão, ou mesmo de explicar uma determinada realidade no mundo. Revelar que foram aplicadas técnicas específicas e que se utilizaram ferramentas sofisticadas, tais como os softwares estatísticos, para dar conta dos dados quantitativos, e afirmar que se empreendeu apenas uma análise "manual" dos dados qualitativos, ou que eles apenas foram lidos para em seguida se dizer, superficialmente, o que se pensa das respostas, é perder metade do esforço de pesquisa, jogando material informacional coletado fora. Não dar a esses dados o tratamento adequado, aplicando em sua análise uma técnica capaz de extrair o máximo de informação relevante, é perda de tempo e de dinheiro. Isso sem considerar a parcialidade, ou mesmo o próprio comprometimento do resultado da investigação.

4 A abordagem Sense-Making foi desenvolvida pela economista e pesquisadora estadunidense Brenda Dervin (1983) tendo tido, desde então, vasta aplicabilidade no campo da Comunicação Social e da Ciência da Informação.

5 O modelo de Ellis (1989) foi ampliado por Ellis, Cox e Hall (1993).

6 Método bastante utilizado nas Ciências Sociais e Humanas, popularizado pela professora de Psicologia Laurence Bardin (2007).

7 Análise do discurso ou análise de discurso é uma prática e um campo da linguística e da comunicação especializado em analisar construções ideológicas presentes em um texto (Rocha e Deusdará, 2005). 
Observando esses trabalhos que não indicaram claramente a técnica de análise de dados utilizada, notamos que em alguns deles foram realizadas análises de dados baseadas em categorias ou em unidades de análise parecidas com aquelas sugeridas por Bardin, embora não se possa afirmar que tenha sido utilizada, efetivamente, a análise de conteúdo, uma vez que essa opção metodológica não foi claramente descrita na metodologia das pesquisas. Em outros dois casos, foram empregados software para a análise qualitativa dos dados, ${ }^{8}$ a saber: QSR ${ }^{9}$ e o NVivo2.0. ${ }^{10}$

Quanto aos procedimentos técnicos, o Estudo de Caso foi, definitivamente, o mais utilizado (sessenta e dois por cento), sendo seguindo pela técnica de Estudo de Casos Múltiplos ${ }^{11}$ (trinta e oito por cento). Isso pode ser compreendido pelo fato de que estudar comportamentos de busca e uso de informação impele o pesquisador, necessariamente, a delimitar bastante seu recorte de pesquisa, restringindo-o a uma instituição ou a um grupo de pessoas, por exemplo. Essa técnica possibilita a observação aprofundada na medida em que concentra os recursos no caso visado e não está sujeita às restrições ligadas à comparação do caso com outros casos (Gil, 2009) muito embora a comparação seja possível quando se emprega o estudo de caso duplo, triplo ou múltiplo. Os resultados de estudos de caso não podem ser generalizados e lançam luz somente sobre o caso investigado, uma vez que foi estudado em profundidade, considerando peculiaridades locais ou intrínsecas ao objeto de estudo.

Dois trabalhos chamaram nossa atenção pela ousadia de sua escolha metodológica. Os autores empregaram ferramentas desenvolvidas por eles próprios para desenvolver seus estudos e testar resultados: um deles criou uma taxonomia enquanto o outro elaborou um modelo baseado no Paradigma da Difusão de Inovações entre consumidores, de Gatignon e Robertson (1991) e o aplicou para estudar consumidores (usuários) de informação. Ambas as pesquisas apontaram na direção da pertinência de suas inovadoras iniciativas e da relevância dos construtos teóricos desenvolvidos a partir delas. Acreditamos que iniciativas como essas são, além de corajosas, desejáveis e salutares para o crescimento teórico e metodológico da CI, na medida em que partem da inovação, da criação, não se limitando à aplicação de instrumentos

8 São softwares projetados para auxiliar os pesquisadores a organizar e analisar dados não-numéricos ou não estruturados.

9 Empresa desenvolvedora de software para pesquisa qualitativa com sede em Melbourne, Austrália, com escritórios no Reino Unido e Estados Unidos.

10 Suporta métodos de pesquisa qualitativos e mistos. Permite reunir, organizar e analisar conteúdos de entrevistas, discussões em grupo, pesquisas, áudio, mídias sociais e páginas web.

11 Gil (2009) esclarece que o Estudo de Caso pode ser empregado para estudar um ou poucos casos. Com relação aos trabalhos que tiveram como lócus mais de um caso, classificamo-los como Estudo de casos múltiplos. 
e técnicas já consolidados e frequentemente reproduzidos em outras pesquisas.

Tendo identificado e analisado as regularidades existentes no que diz respeito aos percursos metodológicos das dissertações e teses selecionadas para compor o corpus documental deste artigo, passamos a descrever e analisar os principais resultados a que chegaram essas pesquisas.

Os resultados dos estudam apontam que, no meio empresarial, o tipo de informação mais importante é o gerencial, por fundamentar as tomadas de decisões dos gestores e atender precisa e rapidamente as necessidades de informação surgidas no dia-a-dia das organizações, favorecendo a solução de problemas em tempo hábil e promovendo vantagens competitivas no mercado. Essa constatação deve orientar as deliberações do profissional da informação no momento da seleção de itens que irão compor os acervos das organizações, bem como no próprio atendimento prestado ao seu público interno, podendo influenciar drasticamente o modo como ele conduz as entrevistas de referência.

Paradoxalmente, as conclusões dos trabalhos analisados revelam inexistirem profissionais da informação atuando nessas organizações, como também nelas não há políticas de informação ou diretrizes formais que orientem os processos, os fluxos, a transferência e a própria gestão da informação. Considerando que os gestores sentem necessidade de se informarem para melhor exercerem suas atribuições, percebendo a informação como insumo para o desenvolvimento e sobrevivência da empresa e como não há profissionais da informação atuando nas organizações, isso nos revela um nicho mercadológico amplo para esse profissional. Há que se investigar as razões pelas quais esses profissionais não estão inseridos nas organizações.

Embora esse não seja o objetivo deste artigo, ousamos arriscar possíveis explicações para esse fato, no intuito de despertar o interesse de outros pesquisadores para o desenvolvimento de estudos futuros. Assim, consideramos que algumas das causas da ausência de profissionais da informação nas organizações perpassem por questões: a) salariais, b) desconhecimento por parte das organizações das potencialidades do bibliotecário, do arquivista ou do documentalista, por exemplo e conforme o caso, c) a habilidade técnica desses profissionais pode não estar voltada para a atuação em unidades de informação com configurações tão peculiares e distintas como as empresariais.

Outra constatação das dissertações e teses estudadas se refere à grande importância dada ao uso de tecnologias para buscar e acessar informação, que modificaram as formas de interação dos usuários com os bancos de dados e interfaces dos sistemas. Os recursos e funcionalidades oferecidos pelos artefatos tecnológicos, cada vez mais atrativos e eficientes, têm transformado 
o modo como o ser humano acessa e usa informação, seja textual, não-verbal, sonora ou audiovisual. Assim, não surpreende que a internet tenha sido apontada como o meio mais utilizado para se acessar informação. As pessoas estão indo menos às bibliotecas movidas pelo "princípio do menor esforço" (Figueiredo, 1994), pelo qual o uso de um canal de informação não é utilizado ser for trabalhoso demais e/ou de difícil acesso - o sujeito irá procurar sempre o caminho mais prático, fácil e rápido, optando por perguntar a alguém presente no local, fazer um telefonema, acessar a internet e, em último caso, sair do prédio onde se encontra, preferindo, muitas vezes, simplesmente desistir de obter a informação.

No entanto, quando o sujeito, na busca por informação, resolve perguntar a alguém, as pesquisas indicaram que o maior grau de confiança é dado à informação profissional (médico, advogado, um colega de profissão, professor, entre outros).

$\mathrm{O}$ último ponto em comum à maioria dos estudos aqui analisados diz respeito ao compartilhamento da informação. Entenda-se por compartilhamento a divulgação da informação de maneira ampla, como aquela que é utilizada em treinamentos de empregados, para lecionar a estudantes, repassar a amigos e parentes, veicular em meios de comunicação, postar em redes sociais na internet, dentre outras possibilidades. Percebe-se que os sujeitos não se informam pensando exclusivamente em resolver problemas e satisfazer necessidades pessoais, havendo uma forte propensão à solidarização com outras pessoas menos informadas, o que as leva a procurar informação para distribuir.

\section{Conclusão}

Com este trabalho de pesquisa, identificamos e analisamos algumas regularidades presentes nos percursos metodológicos adotados nas dissertações e teses sobre comportamentos de busca e uso de informação defendidas em instituições brasileiras na última década e descrevemos e analisamos os principais resultados dessas pesquisas.

Sumarizando as observações que fizemos em nossa análise, elencamos abaixo as escolhas metodológicas tomadas pelos pesquisadores e as principais conclusões a que conseguiram chegar com seus estudos. Não é nosso objetivo afirmar que tais resultados configuram-se como princípios, leis ou teorias, mas somente aglutinar sentenças que esboçam uma "perspectiva de suficiência" no que diz respeito aos percursos metodológicos adotados e uma "perspectiva de verdade" no que se refere ao corolário que se afirma a respeito da realidade, posto de resultam de estudos científicos ao longo de pouco mais de 
uma década (2010 a 2012). Dito isso, ressaltamos que os construtos teórico-metodológicos no campo da CI, no Brasil, apontam na direção de que:

a) os estudos de comportamentos de busca e uso de informação são mais numerosos nas pesquisas de mestrado que de doutorado;

b) há predominância de pesquisas de caráter qualitativo, sendo seguidas pelas quali-quantitativas;

c) os estudos exploratório-descritivos aparecem com mais frequência e os descritivos em segundo lugar;

d) quanto aos instrumentos de coleta de dados das pesquisas quantitativas, os questionários estruturados são os mais utilizados, havendo o uso de softwares estatísticos para tabulação e análise;

e) quanto aos instrumentos de coleta de dados dos estudos qualitativos foram identificados como sendo de uso frequente os questionários e entrevistas semiestruturadas;

f) como técnica de análise dos dados das pesquisas qualitativas, foram recorrentes a análise de conteúdo e, em segundo lugar, a análise do discurso.

g) o estudo de caso e o estudo de casos múltiplos foram utilizados na grande maioria dos trabalhos;

h) a informação gerencial é a mais importante nas organizações;

i) inexistem políticas, diretrizes, processos e fluxos de informação formalizados nas organizações devido à ausência do profissional da informação;

j) as tecnologias da informação e da comunicação alteraram sobremaneira o modo como interagimos com a informação, como realizamos a busca e como a acessamos,

k) a internet é o meio de acesso à informação mais procurado pelos sujeitos;

1) havendo necessidade de obter informação através da consulta a uma pessoa, a informação fornecida por profissionais (professores, engenheiros, médicos, por exemplo) é dotada de maior confiabilidade, na percepção dos sujeitos das pesquisas;

m) a informação também é buscada e acessada para ser compartilhada e, não necessariamente, apenas para uso pessoal.

Em nossa visão, parece haver coerência nas escolhas metodológicas feitas pelos pesquisadores dos trabalhos analisados. Entendendo a Ciência da Informação como uma ciência social, é aceitável que ela utilize métodos e técnicas advindas das Ciências Sociais, principalmente, sendo de nosso co- 
nhecimento que a CI não revelou, ainda, ser capaz de gerar resultados satisfatórios e confiáveis através do emprego de metodologias próprias.

No entanto, a simples reprodução de métodos e técnicas já conhecidos, sendo somente aplicados, por exemplo, em diferentes recortes geográficos, cronológicos, de grupos sociais, faixas etárias ou etnias, apenas contribuirá para o conhecimento limitado da realidade.

Para o avanço das ciências, é primordial estimular a criatividade do pesquisador, de modo que ele possa analisar o mundo por outros meios, de outras formas, por outras "lupas", nem sempre melhores ou piores, mas diferentes. É na diferença que se apresenta a perspectiva do novo, da descoberta, do avanço.

\section{REFERÊNCIAS}

Araújo, C. A. A. 2003. "A ciência da informação como ciência social". Ciência da Informação, Brasília, 32 (3) (set./dez.): 21-27.

_ 2009. "Correntes teóricas da ciência da informação". Ciência da Informação, Brasília, 38 (3) (set./dez.): 192-204.

Bardin, Laurence. 2007. Análise de conteúdo. Lisboa: Edições 70.

Bettiol, E. M. 1990. "Necessidades de informação: uma revisão". $R$. Biblioteconomia de Brasília 18 (1): 59-69 jan./jun.

Capurro, R. 2003. "Epistemologia e Ciência da Informação". Em Encontro Nacional De Pesquisa Em Ciência Da Informação, 5, 2003, Belo Horizonte. Anais do quinto Encontro Nacional de Pesquisa em Ciência da Informação, 1-23. Belo Horizonte: ANCIB. Acesso em: 30 jun. 2013, http://www.capurro.de/enancib_p.htm

Case, D. O. 2007. Looking for information. 2. ed. Amsterdam: Elsevier.

Dervin, Brenda. 1983. "An overview of Sense-making research: concepts, methods and results to date". International Communications Association Annual Meeting. Dallas, May, 1983.

Ellis, D., D. Cox e K. Hall. 1993. "A comparison of the information seeking patterns of researchers in the physical and social sciences". Journal of Documentation, London, 49 (4): 356-369.

Ellis, D. 1989. "A behavioral model for information retrieval system design". Journal of Documentation 45 (3): 171-212.

Figueiredo, N. M. 1994. Tópicos modernos em Ciência da Informação. Lorena: Centro Cultural de Teresa D'ávila.

Flanagan, John C. 1954. "The critical incidental technique". American Institute for Research and University of Pittsburgh. Psycological Bulletin 51 (4) (jul.).

Gatignon, H. e T. S. Robertson. 1991. "Innovative decision processes”. Em T. S. Robertson e H. H. Kassarjian, Handbook of consumer behavior, 316-348. New Jersey: Prentice-Hall.

Gil, A. C. 1996. Como elaborar projetos de pesquisa. 3. ed. São Paulo: Atlas. 
González de Gómez, M. N. 2000. "Metodologia de pesquisa no campo da Ciência da Informação”. DataGramaZero-Revista de Ciência da Informação 1 (6) (dez.). Acesso em: 15 mar. 2013, http://www. dgz.org.br/dez00/Art_03.htm

2007. "Para una reflexión epistemológica sobre La ciência de La información”. Signo y Pensamiento 50 (XXVI) (ene.-jun.): 47-61.

Lakatos, E. M. e M. A. Marconi. 1996 Técnicas de pesquisa: planejamento e execução de pesquisas, amostragens e técnicas de pesquisas, elaboração e interpretação de dados. 3. ed. São Paulo: Atlas.

Linares Columbié, R. 2010. "Epistemología y ciência de la información: repensando um diálogo oincluso”. Acimed, Havana, 21 (2). Acesso em: 18 mar. 2012, http://www.acimed.sld.cu/index.php/ acimed/article/viewArticle/52/18

Pinheiro, L. V. 2005. "Processo evolutivo e tendências contemporâneas da Ciência da Informação". Informação E Sociedade: Estudos, João Pessoa, 15 (1) (jan./jun.): 13-48.

Rabello, R. 2012. "A Ciência da Informação como objeto: epistemologias como lugares de encontro". Perspectivas em Ciência da Informação 17 (1) (jan./mar.): 2-36.

Richardson, R. J. 1999. Pesquisa social: métodos e técnicas. 3. ed. São Paulo: Atlas.

Rocha, D. e B. Deusdará. 2005. "Análise de Conteúdo e Análise do Discurso: aproximações e afastamentos na (re) construção de uma trajetória”. Alea: Estudos Neolatinos 7 (2) (jul./dec.):305-322, Rio de Janeiro.

Silva, C. R. O. 2004. Metodologia e organização do projeto de pesquisa: guia prático. http://www.ufop.br/demet/metodologia.pdf Acesso em: 18 mar. 2013.

Silva, M. G. 2008. Informação e a população carcerária: estudo de usuários de informação na Penitenciária José Maria Alkmim, Ribeirão das Neves - MG. Dissertação (Mestrado em Ciência da Informação), Universidade Federal de Minas Gerais, Belo Horizonte.

Wilson, T. D. 1996. "Information needs and uses: fifty years of progress?", em Fifty years of information progress: a Journal of Documentation review, B. C. Vickery (org.), 15-51. Londres: Association for Information Management. Acesso em: 30 jun. 2013, http://informationr.net/tdw/publ/papers/1994FiftyYears.html

Para citar este artículo:

Rodrigues Tabosa, Hamilton, José Mauro Matheus Loureiro y Virgínia Bentes Pinto. 2016. "Análise de regularidades metodológicas em pesquisas brasileiras sobre comportamentos de uso e usuários da informação." Investigación Bibliotecológica: Archivonomía, Bibliotecología e Información 70: 249-267. http://dx.doi.org/10.1016/ j.ibbai.2016.10.011 